\title{
Pragmatic Competence Cultivation of Non-English Majors
}

\author{
Zhihui Sun \\ Foreign Language College \\ Jingchu University of Technology \\ Jingmen, Hubei, China, 448000
}

\author{
Biqian Zhu \\ Foreign Language College \\ Jingchu University of Technology \\ Jingmen, Hubei, China, 448000
}

\begin{abstract}
For the current situation of pragmatic competence cultivation of non-English majors in colleges of our country, in order to meet the requirements of College English course and actual requirements of social development, teachers should pay attention to the initiation of cultural knowledge, improve the level of pronunciation and intonation of students, center on students, adopt task-based teaching method, create the conditions to use English, make students truly achieve the ultimate goal of learning language, and meet the actual requirements of social development and personal development.
\end{abstract}

Keywords-English pragmatic competence; comparison between Chinese and western culture; task-based teaching method

\section{INTRODUCTION}

In 2004, the College English Curriculum Requirements (Trial Implementation) issued by Ministry of National Education stipulates: in college English teaching, the goal of students' listening and speaking shall reach the level to have daily conversation with British and American. This shows that the goal of college English teaching reform changes from the previous pattern that focuses on reading comprehension and gives consideration to listening and speaking to the pattern that focuses on listening and speaking, comprehensively cultivates students' abilities in comprehensively using English and makes them use English to communicate effectively in future work and life. Pragmatic competence refers to the ability to correctly and properly use language to communicate with others. Therefore, the orientation of college English teaching reform exactly and clearly embodies the requirements for cultivation of students' pragmatic competence.

\section{CURRENT SituAtion OF PRAGMATIC COMPETENCE Cultivation OF NON-English MAJORS IN OUR COUNTRY}

\section{A. Students Have Low Language Productive Competence and No Strong Self-confidence}

Although most of non-English majors have received twelve years of test-oriented English education, they have weak English foundation, insufficient vocabulary and ordinary grammatical basis. In class, they are afraid to boldly open their mouth to use English to express their opinions. When they do dialogue practice, they often say incoherent phrases or sentences. When they answer questions, the content is simple,

Subject content: This article is one of the achievements of "Research on Training Mode of Applied Talents of Business English Major in Local Higher Education Institution Under the background of Transformation" (No.:

2014A038) of leading group of education science planning in Hubei Province in 2014. lacking logic and expansion. When the teacher asks a question in the form of general question, a lot of examinees answer it only by using Yes or No. It is difficult for them to go deep into the topic, or they open their mouth only when they first write them down and have the encouragement of teacher. They cannot speak English fluently. Poor language using ability results in poor psychological quality. Besides, the diffident psychology further makes students lose interest in language learning under the condition that there are too many students in a class and the teacher cannot give consideration to all students. The existence of this kind of phenomenon seriously disturbs college English teaching.

\section{B. Students Have Nonstandard Pronunciation and Intonation, Which Causes Communication Barriers}

Non-English majors are from all provinces and cities and have different regional accent. Therefore, in pronunciation of English, they have inaccurate or even wrong pronunciation because of disturbance of regional accent, such as the mispronunciation of " $\mathrm{x}$ " and " $\mathrm{s",}$ or differences between /æ/ and $/ \mathrm{e} /, / \mathrm{d} /$ and $/ \theta /$. In polysyllabic words, they repeatedly make mistakes in word stress. In addition, when reading sentences or paragraphs, students ignore pausing according to sense-group. They only read at will without distinguishing rise and fall of intonation. And their pronunciation is inaccurate. It leads to the fact that students who read and students who listen do not know what the content is after reading. This kind of learning disabilities in pronunciation and intonation cause communication barriers and further bring psychological barriers of social intercourse that has unfavorable effects on the improvement of students' pragmatic competence.

\section{Students Have Low Cultural Literacy and Ignore Cultural Background Knowledge, Which Cause Pragmatic Errors}

In dialogue practice of oral English in class, it is found that students often do not understand the reasons of authentic English expression and make pragmatic mistakes under the disturbance of mother language. For example, when the teacher praises a student, the teacher says, "Your English is very good", and the student replies, "No, just so-so". Students often become humble, which does not conform to the communication mode of English. For the praise, the student should reply, "Thank you". This kind of communication failure often inevitably relate to the fact that students do not 
understand background knowledge of western culture and communicating habits. Of course, it also has relationship with the fact that most teachers lack the concept of pragmatic awareness cultivation in their teaching, so that students cannot obtain pragmatic connotations of English. So when using English to communicate, they have no choice but to mechanically apply English vocabulary and grammar knowledge that they learn according to their Chinese pragmatic competence, and make pragmatic mistakes.

\section{Traditional Teaching Method Is Still Dominative, Ignoring the Cultivation of Pragmatic Competence of Students}

At present, there are too many students in the class of nonEnglish major, so it is difficult for teachers to give consideration to every student. Besides, teachers have heavy teaching task and keep limited time for student practice in each class, and they often focus on teaching and take much more time for lectures than that for students' practice. Students just listen and accept knowledge passively. Teachers do not create appropriate conditions for students to learn language, so the pragmatic competence of students cannot be improved. Especially for the students that have weak learning foundation and ability, the learning effect is not obvious.

\section{Suggestions on Pragmatic COMPETENCE Cultivation OF NON-ENGLiSH MAJORS}

\section{A. Improve Level of Pronunciation and Intonation of Students, Help Students to Eliminate Psychological Barriers}

Pronunciation and intonation are closely related to the improvement of ability of listening and speaking. Without pronunciation and intonation, human language is out of the question. Good pronunciation basis helps the formation of language skills such as listening, speaking, reading and writing. For the students whose mother language is not English, their accurate pronunciation depends on their accurate imitation of English pronunciation. At present, most students do not have a complete and thorough comprehension of pronunciation knowledge because they have been influenced by the pronunciation of dialect in their hometown. Therefore, when teaching freshman, teachers shall make full use of the computer to play standard and authentic English recording, use such teaching methods as display, contrast and comparison, focus on students' exercise, start with the cultivation of ability to listen and distinguish pronunciation and intonation, closely connect the training of listening, pronunciation and oral expression, pay attention to the training of basic skills and the practical application. The concrete operation can refer to intensive reading and listening and speaking courses in college English, use modern multimedia technology to take all kinds of listening and speaking activities, such as listening practice, word reading, text reading, lecture, role play, poetry reading, storytelling, restatement and debate in and after class. When training students' ability of listening and speaking, teachers shall play a guiding role and help students to improve pronunciation and intonation. They can also ask students to learn mutually after class and let the students with good foundation help the students with poor foundation. Besides, in the whole teaching process, teachers shall teach students in accordance of their aptitude and make individual tutorship according to students' individual difference, listen to students' problems carefully, give them improvement suggestions, and make students better improve their pronunciation and selfconfidence of learning.

\section{B. Pay Attention to the Initiation of Culture, Contrast Chinese and Western Culture and Eliminate the Influence of Cultural Factors}

Culture and language are inseparable. The development of culture can drive the development of language. Language is the carrier of culture and reflects the culture. Any kind of national language has innumerable links with the culture of this nationality. The application of language and words and the communicative function of language cannot do without understanding the cultural background of this language and the national conditions. Therefore, teachers shall ask students to grasp language rule. What's more, they shall let students understand the world outlook and the values of the people who use this language and let students know how they use language to reflect their thoughts and behaviors. Only when having deep comprehension of socio-cultural background, they can truly master a language. In order to let them actively absorb and blend into the new cultural environment, the specific ways are as follows:

1) In English teaching, teachers shall focus their vocabulary teaching on revealing words and expressions in Chinese and English with the same or opposite connotation: For example, enumerate cultural phenomenon to let students think them in comparison: what's the general characteristic of these phrases, namely, as weak as water, drink like a fish, all at sea? And remind students whether these phrases have relationship with water. While these phrases in Chinese such as cut the weeds and dig up the roots, at the end of one's rope, good weather for the crops, have any relationship between each other? Give students hint to guide them to realize that agriculture and land are very important in China, a big agricultural country. So some phrases related to agriculture and land are produced. Britain is an island country surrounded by water, so there are many phrases related to water and fish in English. Because Chinese language and English language have different cultural background, people with different cultural background hold different ideas for the same things, and the same things are endowed with different cultural connotations. For example, the word of "dog", in terms of linguistic meaning, has no difference in Chinese and Western, both indicating the animal with the same characteristic. But it has large difference from cultural significance. For Chinese people, "dog" has derogatory sense and it is the pronoun of baseness and impudence, such as brutal and cold-blooded, threatening people like a dog on the strength of its master's power. While English people like "dog”, such as the English proverbs "Every dog has its day", "Give a dog an ill name and hang him". In the traditional concept of western people, "dog" 
is the intimate friend of "people", such as the English proverb, "Love me, love my dog". Therefore, English people often regard "dog" as people and it has no derogatory sense, such as "He is a lucky dog".

2) Guide students to pay attention to the differences in language forms and application caused by Chinese and English cultural differences in daily life communication: The contents of this aspect are very important and also very rich, because it has close relationships with different communication situation, interpersonal relationship, etiquette and custom as well as values, which is mainly reflected in greetings, salutation and praise that have different modes and means of expression. For example, students often call the author "Teacher Sun", which has relationship with the frequently-used job title in Chinese thinking. But in English, they are used to using Mrs. or Mrs. and surname, or they only use job title. Another example, in farewell, students often walk away immediately after they say, "I must go, bye". But according to western custom, we should thank the host before leaving, such as "Thank you for a wonderful dinner", "I enjoyed our talk. Thank you very much".

3) Guide students to avoid mechanical correspondence of Chinese and English words and mechanical application of Chinese expression structure: In dialogue in classroom, students often use "Of course" to answer questions. In Chinese, "of course" means affirmation. But they don't know that it violates politeness principle in English. In English, it means "it is clear and this is no need to ask". It is a kind of irony for listeners. Besides, in communication process, students often use some fuzzy words, such as probably, maybe, nearly and almost, etc. They reckon without that western people, especially American people, have open and straightforward character. They have linear type of thinking of speaking and get straight to the point. Excessive use of fuzzy words will make western people think that the speaker is speaking insincerely, or give them the impression of meaning ambiguity. Therefore, the vagueness of meaning of Chinese language expression violates the maxim of quality in crosscultural communication and leads to the failure of communication. So in teaching, teachers shall timely correct the mistakes made by students, teach students some pragmatic knowledge, such as context, conversational implication, cooperative principle and politeness principle.

4) Teachers supplement more short sentences of oral English to help students to learn English and understand cultural connotation, teach students to learn and accumulate after class and obtain cultural knowledge of English-speaking countries through reading newspapers and periodicals, literary works and using a variety of modern media tools, so that they can change from classroom learning to after-class learning. We can use this approach to cultivate students' keen interest in learning English and make most of students realize their change from passive learning to active learning.

\section{Center on Students, Adopt Task-based Teaching Method and Enhance Oral Training for College Students}

The task-based teaching method has comprehensive, cooperative, interactive, practical and participative characteristics, so its advantages receive wide recognition and attention in English language teaching. Task-based teaching method makes students actively learn with clear goal and makes them find and master language rule by way of participation, practice, exchanges and cooperation in the process of performing a task,. While the relaxed and active classroom atmosphere of task-based teaching method, also greatly eliminates the negative psychology and interiority complex of students whose oral English is poor, and impels them to participate in learning tasks and feel the happiness and achievements brought by fulfilling a task. For example, in an oral English class, we can let students use English to introduce each other. Before class, teachers can let students prepare their personal information in English, including date of birth, constellation, interest and telephone number. In class, divide the students into two groups and let them sit together to form an inner circle and an outer circle. The number of students in the two circles is the same and they sit face to face. Within the specific time, such as one minute, the students can use English to ask questions and communicate with the others who sit in front of them so as to get information from each other. When the time is up, the teacher says, "Next one", the students in the outer circle keep still and the students in the inner circle move right and begin the next round of dialogue with the second student in the opposite and the rest can be done in the same manner. After ten minutes, students complete their information collection and make an introduction in English with the student information collected by them. In the implementation of the whole task, it centers on students and the teacher only guides them and corrects their mistakes. Task-based teaching method lets students' class presentation become free and relaxed after elaborate preparation. They can experience the joy of success when they solve problems in practice. Their self-confidence is strengthened naturally. It can also arouse students' initiative, enthusiasm and creativity of learning and bring significant learning effect. Therefore, teachers should elaborately design diversified and interesting teaching tasks according to students' actual life and hobbies and interests, which can not only enrich students' extracurricular activities, but also vivify oral English class and provide more opportunities for students to express oral English.

\section{Combine the Study Inside and Outside Classrooms, Create the Conditons of English Application and Cultivate Oral Communicative Ability}

The cultivation of pragmatic competence cannot be completed in one day. Except for class learning, students must make extracurricular practices of language in large and expand their channels of oral communication in different ways. At present, English activities in colleges are rich. Teachers should encourage students to actively participate in the communication of English corner, English speaking contest and English debating competition activities and make students have more opportunities to communicate with others by using English. Before participating in these activities, students often make preparations in advance, which will certainly promote 
their pragmatic competence. Teachers can also recommend English newspaper or magazines to students, ask them to listen in English programs on the broadcasting station, participate in various types of English lectures, or watch original English films, and participate in English talent show or Christmas party. Thus, the combined study inside and outside class will make students have more opportunities of language input and output, strengthen the cultivation of cultural awareness and better improve their pragmatic competence. Meanwhile, teachers shall check and supervise students' participation in extracurricular activities, responsible for their extracurricular activities, and provide suggestions. In class, teachers shall provide opportunities for students to show their achievements of extracurricular learning and then further inspire students.

\section{E. Self-improvement of Teachers}

In the teaching process, teachers are not only the planner of teaching contents, but also the conductor of teaching activities, and they need lifelong learning to improve themselves. Therefore, teachers shall first learn pragmatic knowledge and grammar knowledge very well and know cultural background of western English-speaking countries. In class, when students make pragmatic mistakes, the teacher can immediately find and correct these mistakes in time and make students avoid a mistake habit. Meanwhile, teachers shall continuously study and discuss teaching strategies to improve their teaching level. A harmonious and vivid teaching class can help students to inspire with their learning motivation, develop their interest in learning foreign language and make the class of foreign language become a real class of communication.

\section{CONCLUSION}

The uppermost and ultimate goal of language learning is to fluently and properly communicate with the users of target language and achieve the transmission and exchange of information. The improvement of pragmatic competence of non-English majors in colleges needs joint efforts of teachers and students. As our teaching objective focuses on the cultivation of pragmatic competence, we should help students to overcome psychological barriers, improve their pronunciation and intonation, provide real and effective English communication environment of students, cultivate the consciousness of cultural comparison, and increase students' comprehension of culture in the country of target language, so that students reduce pragmatic mistakes, improve their pragmatic competence and truly meet the requirements of life and work in the future.

\section{REFERENCES}

[1] Wang Zhuoqun, Qian Xiufang. Improve Pragmatic Competence, Reduce Pragmatic Errors [J], Culture and Education Forum, 2007(12)

[2] Dou Jing. Highlight Oral Training and Improve Students' Pragmatic Competence [J], Education Exploration, 2011(3)

[3] Mu Xiangrui. Improve Students' Pragmatic Competence in College English Teaching [J], Exam Weekly, 2010 (5)

[4] Jiang Zhanhao, Zhou Baoguo. Research on Pragmatic Competence Assessment of Learners [J], Foreign Language Teaching, 2012, 33(5)
[5] Chen Fang. How to Cultivate Students' Cultural Literacy to Improve Their Pragmatic Competence [J], Journal of Jiamusi Education Institute, 2013(8)

[6] Huang Xiaoyan. Cultivation of English Pragmatic Competence of Students in Higher Vocational Colleges [J], Journal of Jiangsu University of Technology, 2012, 18(1) 